\title{
Experimental Investigation on the Early Stage Spray Characteristics with Biodiesel and Diesel
}

\author{
ShenghaoYu ${ }^{1}$, Bifeng. Yin ${ }^{1}$, Shuai Wen ${ }^{1}$, Xifeng $\mathrm{Li}^{1}$, Hekun. Jia ${ }^{1}$, Jianda. $\mathrm{Yu}^{2}$ \\ ${ }^{1}$ School of Automotive and Traffic Engineering, Jiangsu University, Zhenjiang 212013, China \\ ${ }^{2}$ Wuxi Fuel Injection Equipment Research Institute, Wuxi 214063, China \\ *Corresponding author: yshujs@163.com
}

\begin{abstract}
The early stage spray characteristics have a great impact on the secondary atomization progress, and thus affect the engine combustion and emission performances. The experimental investigation of the early stage spray behaviors with biodiesel and diesel was carried out by employing a laser-based Mie-scattering method. The results show that the spray tip penetration for biodiesel is higher than that for diesel at the early stage spray under the same injection pressure. Moreover, the early stage spray tip penetration can be longer under high injection pressures for two fuels. Besides, the early stage spray cone angle for biodiesel is narrower than that for diesel, and the spray cone angle is especially higher than biodiesel by $25.8 \%$ after start of injection time of $0.01 \mathrm{~ms}$. Furthermore, under the same injection condition, the difference of early stage spray area between diesel and biodiesel is not obvious, while the spray volume for biodiesel is larger than that for diesel, and also the spray volume can be enlarged by increasing injection pressure for both fuels.
\end{abstract}

\section{Keywords}

Spray characteristics; Mie-scattering; Biodiesel; Diesel

\section{Introduction}

For modern diesel engines, soot and nitrogen oxide are the two main emissions which are mainly influenced by mixture quality of air and fuel, and the emission characteristics are largely governed by atomization and spray processes [1-4]. Biodiesel, derived from the waste cooking oil and a kind of renewable energy, has been widely used as an alternative fuel for diesel engines. It is clear that the use of biodiesel in diesel engine can improve favorable emissions performance [5-9]. Although the importance of biodiesel in reducing diesel engine emission performance has been acknowledged, the research on early stage spray characteristics of biodiesel is still far from sufficient. The early stage spray dominates the secondary spray progress and the mixture quality of fuel and air, and thus affects the atomization quality of biodiesel. Therefore, it is important to define the effects of biodiesel at the early stage spray characteristics.

Wang et al. $[10,11]$ studied the near-field primary spray characteristics of different split injection strategies by using ultra-high speed imaging method. Their results indicated that the second split injection cause smaller spray area and shorten penetration during the early stage spray, and also the larger late injection stage can increase the spray area and the penetration. Moreover, they found that the strong primary collision can be caused by improving the injection pressure and shortening dwell split injection, thus the spray area and the spray cone angle increase, while the spray tip penetration decreases at the same time. And they also found that the long duration of the first injection enhances the primary collision. Wang et al.[12] also studied the spray behaviors of emulsified diesel blended with water through schlieren technique. They concluded that the penetration increases as the magnitude of water increases, while the spray cone angle, spray volume and area decrease. Mo et al. [13] carried out an experimental research on the spray and atomization behaviors with soybean biodiesel and $20 \% \mathrm{n}$-butanol biodiesel blend respectively by schlieren and particle diameter image analysis techniques (PDIA) techniques. Their results showed that the penetration and droplet diameters of BD100 are higher than that of BD80. Li and Xu [14] used an ultra-high speed camera to study the influence of injection and ambient pressure on the spray behaviors, such as spray penetration and tip velocity. They concluded that the spray peak velocity is related to the change of two-stages of spray. Ding et al.[15] investigated the near nozzle spray patterns with four different fuels through experimental method, and the results suggested that the hydraulic flipping regime is extremely different for four fuels under different injection pressures. Xie et al.[16]experimented on the spray characteristics for different biodiesels and their blends with diesel under different injection conditions. They observed that the penetration increases as the blend ratio of biodiesel increases, while the spray cone angle becomes narrower than that of diesel. 
The literature review mainly focused on the initial breakup with traditional diesel or the secondary spray and atomization characteristics with biodiesel or its blends. However, the research on the early stage spray characteristics when using biodiesel is still insufficient. In addition, the research on the early stage spray with biodiesel is of great importance for better understanding of biodiesel spray characteristics, because the early stage spray dominates the secondary breakup and air/fuel mixture quality, and also can provide helpful basis for improving the atomization quality of biodiesel. In consequence, due to the poorer quality of biodiesel sprays in comparison with diesel, the impact of biodiesel on the early stage spray characteristics requires an in-depth study. Therefore, our research mainly focuses on the early stage spray characteristics of biodiesel and diesel under the condition of different injection pressures (50MPa, $90 \mathrm{MPa})$ and the fixed ambient pressure of $0.1 \mathrm{MPa}$. The early stage spray characteristics, containing spray tip penetration, spray cone angle, spray evolution images at the early stage spray, spray area and spray volume, were employed respectively to investigate the early stage spray characteristics of diesel and biodiesel. It is of great importance to better understand biodiesel spray characteristics at the early stage spray, which can help improve the quality of secondary atomization for biodiesel effectively. In order to analyze the early stage spray characteristics, a laser-based Mie-scatting method was adopted by using Nd:YAG laser beam visualization system and a CCD camera.

\section{Material and methods}

In this research, all the experimental ambient temperatures were set to300K. Figure 1 shows the experimental equipment diagram for studying the early stage diesel and biodiesel spray characteristics. The experimental equipment diagram consists of a 2D image recorder system, a common rail injection system and a laser beam system (Nd:YAG Laser). 2D image recorder system consists of a CCD camera (500 fps), and image acquisitionprocessing system. The early stage macro spray images (the resoltion of the camera is $1600 \times 1200$ pixels) were captured by using the CCD camera with a camera filter. The common rail injection system consists of a high injection pump, high pressure pipes, electromotor, common rail and a sac single diesel nozzle. The high injection pump was driven by electromotor to provide different high injection pressures. Furthermore, the delay time among the laser beam, CCD camera and injector nozzle were set by a delay controller.

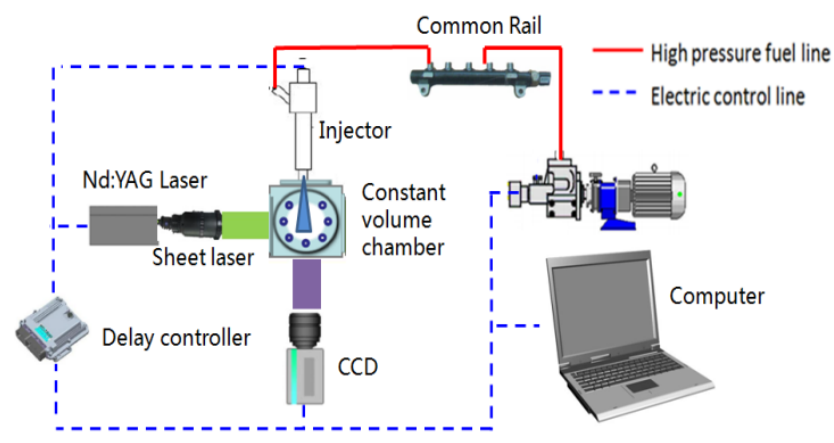

Figure 1. Experimental equipment diagram

In order to study the early stage spray characteristics for diesel and biodiesel, two fuels were selected in the experiment, biodiesel (B100) was derived from waste cooking oil, and conventional diesel (B0) were used as experimental fuels. B0 corresponds to 0\% biodiesel - 100\% diesel; and B100, 100\% biodiesel - 0\% diesel, respectively. The main physical properties of B0 and B100 are listed in Table1. It can be found in Table1that the physical properties of B100 are all higher than those of B0.

Table1 Physical properties for diesel and biodiesel

\begin{tabular}{llllll}
\hline Fuel type & $\begin{array}{l}\text { Density(kg/ } \\
\mathrm{m} 3)\end{array}$ & $\begin{array}{l}\text { Dynamic } \\
\text { viscosity(pa s) }\end{array}$ & $\begin{array}{l}\text { surface } \\
\text { tension(N/m) }\end{array}$ & $\begin{array}{l}\text { Boiling range/ } \\
{ }^{\circ} \mathrm{C}(\mathrm{T} 10)\end{array}$ \\
\hline Diesel(B0) & 830 & 0.0021 & 0.024 & 220 \\
Biodiesel(B100) & 870 & 0.0039 & 0.028 & 330
\end{tabular}

Table 2 represents the experimental working conditions, a single sac nozzle was selected in this study, and two different fuels were adopted to study the early stage spray characteristics. Injection pressure was set as 50MPa and $90 \mathrm{MPa}$ respectively; the ambient pressure was fixed as $0.1 \mathrm{MPa}$; and the ambient temperature was set as $300 \mathrm{~K}$. The present research mainly focused on the early stage spray behaviors, so the after start of injection (ASOI) time changed from $0 \mathrm{~ms}$ to $0.1 \mathrm{~ms}$, and the injection duration was set as $2 \mathrm{~ms}$.

Table2 Experimental working conditions 


\begin{tabular}{ll}
\hline Experimental system & Parameters \\
\hline Fuel & Diesel (B0), Biodiesel(B100) \\
Nozzle type & Sac-nozzle \\
Diameter of nozzle hole & $0.2 \mathrm{~mm}$ \\
Injection pressure & $50 \mathrm{MPa} .90 \mathrm{MPa}$ \\
Ambient pressure & $0.1 \mathrm{MPa}$ \\
Ambient temperature & $300 \mathrm{~K}$ \\
Injection duration & $2 \mathrm{~ms}$ \\
After start of injection (ASOI) & $0 \mathrm{~ms} \sim 0.1 \mathrm{~ms}$ \\
\hline
\end{tabular}

\section{Results and discussion}

This study included comparison of early stage spray images obtained from the spray test platform with a laserbased Mie-scattering method under different injection pressures (50MPa, 90MPa) with diesel (B0) and biodiesel (B100). The results in Figure 2 show the evolution of the early stage spray images under injection pressures of $50 \mathrm{MPa}$ and $90 \mathrm{MPa}$ respectively, and the ambient pressure was fixed at $0.1 \mathrm{MPa}$. The captured images were used to analyze the early stage macroscopic spray characteristics. All the recorded macro spray images were processed by MATLAB software (binary processing) to obtain the macro spray characteristics. In order to improve the measurement accuracy, eight spray images are taken for each given moment, and the spray characteristics are the average of those of the eight times. In addition, the fundamental macro spray characteristics of diesel (B0) and biodiesel (B100) were analyzed and compared in terms of spray tip penetration[10], the cone angle which is formed by the spray considering $60 \%$ of the penetration, spray area and spray volume.

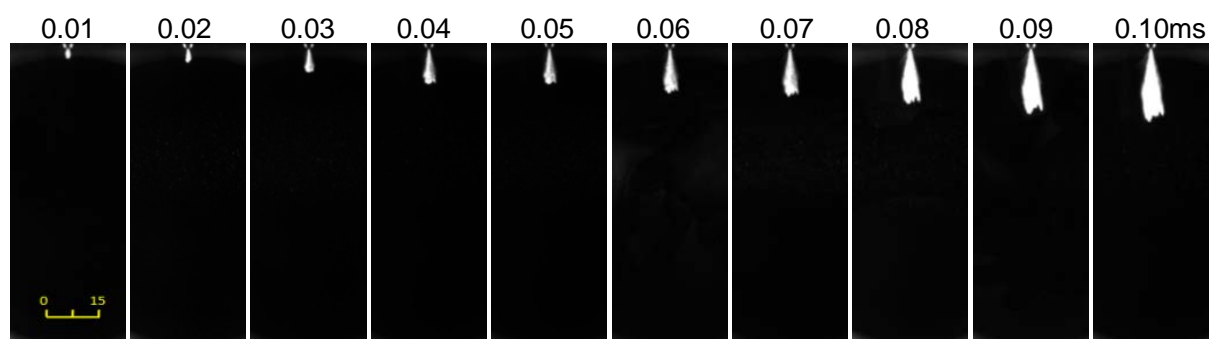

(B0)

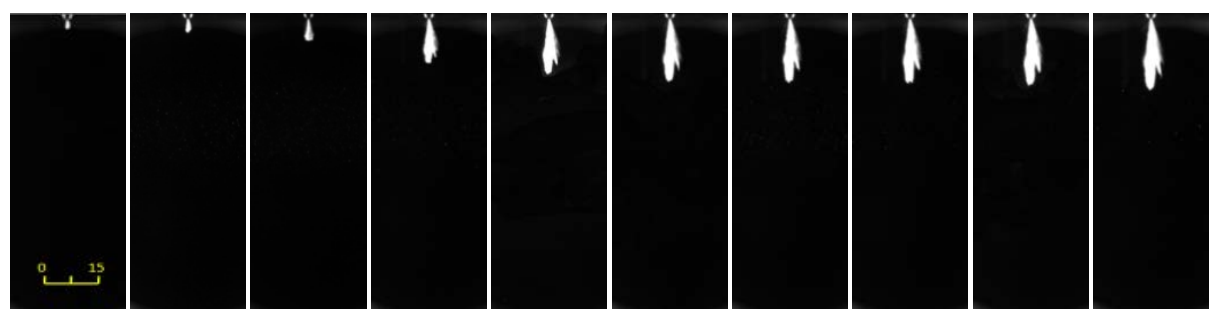

(B100)

$50 \mathrm{Mpa}$

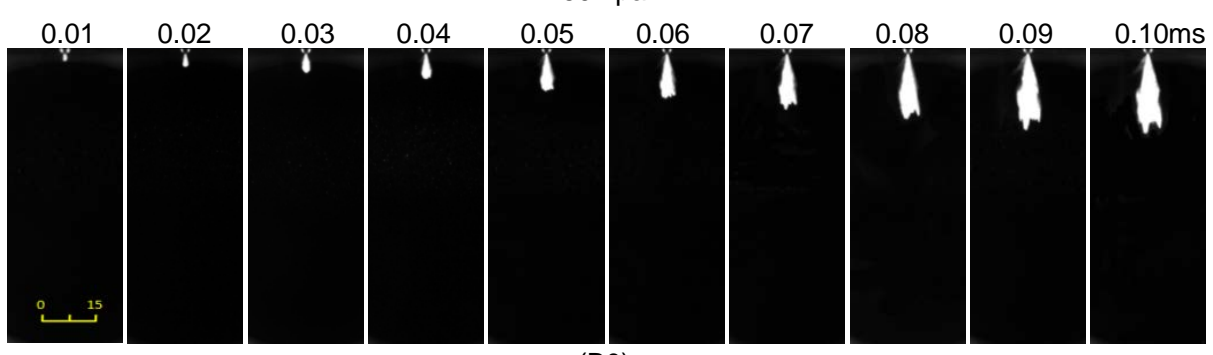

(B0) 

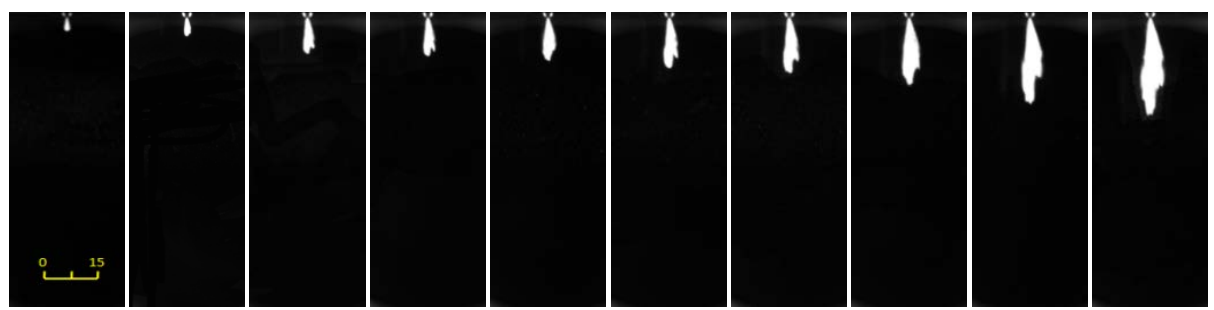

(B100)

$90 \mathrm{MPa}$

Figure 2. Spray morphology (time in ms ASOI) for diesel (B0) and biodiesel (B100) under different injection pressures Spray tip penetration

The results in Figure 3 show the evolution of the early stage spray tip penetration for diesel and biodiesel under different injection pressures (50MPa, 90MPa) and the fixed ambient pressure of $0.1 \mathrm{MPa}$. The results in Figure 3 indicate that the spray tip penetration for biodiesel is higher than that for diesel under the same injection pressure. It is mainly due to the larger surface tension and viscosity of biodiesel, which can inhibit the progress of the early stage spray and atomization, and thus result in large injection momentum and velocity for biodiesel at the nozzle exit. It is favorable for increasing the early stage spray tip penetration. Moreover, the biodiesel in the injector nozzle can promote the friction between the fuel and the inner wall surface of injector orifice, as a result of the higher viscosity of biodiesel. In addition, it can also be found that the early stage spray tip penetration is extended by increasing the injection pressure, because high injection pressure can increase the injection velocity at the nozzle exit.

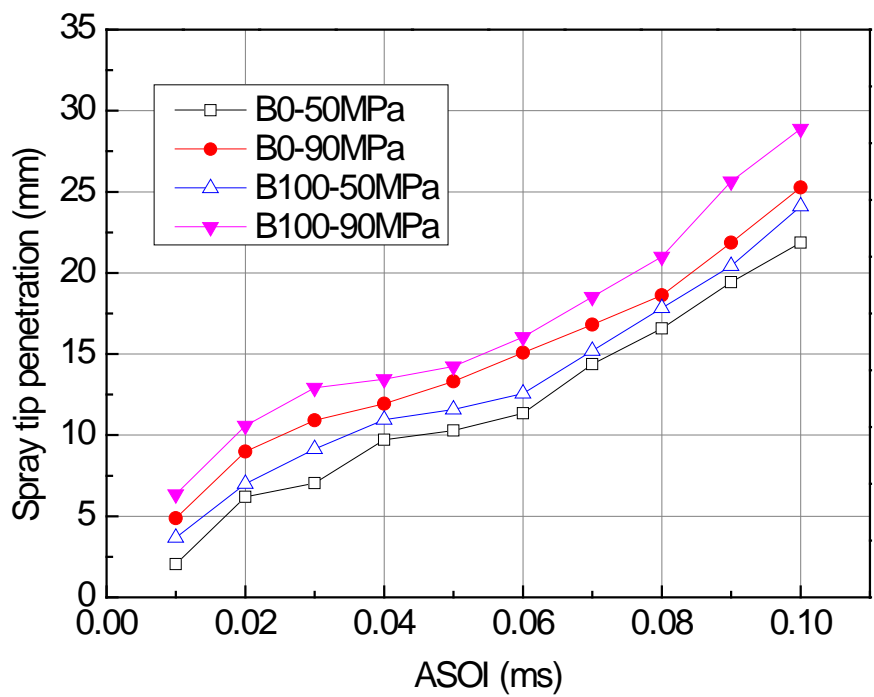

Figure 3. Spray tip penetration for diesel and biodiesel under different injection pressures Spray cone angle

The results in Figure 4 show the evolution of the early stage spray cone angle for diesel and biodiesel under different injection conditions and the fixed ambient pressure of $0.1 \mathrm{MPa}$. It can be found that the spray cone angle was wider for B0 when compared to B100. Moreover, the big difference for spray cone angle is at the beginning of injection. For instance, the spray cone angle for B0 is higher than that forB100 by $25.8 \%$ after start of injection time of $0.01 \mathrm{~ms}$ under the injection pressure of $50 \mathrm{MPa}$. It is mainly due to the higher surface tension for biodiesel, which can suppress the increase of radial velocity of the jet at the nozzle exit and the collapse of spray for biodiesel. As a result, the early stage spray cone angle of B100 is narrower than that of B0. Furthermore, the larger early stage spray cone angle of diesel means strong interaction between fuel and air at the early stage spray, which can improve the quality of primary spray and atomization greatly. By contrast, the quality of primary spray for biodiesel is poor. Finally, it can also be found that the difference of the early stage spray cone angle is not obvious for the same fuel under different injection pressures. 


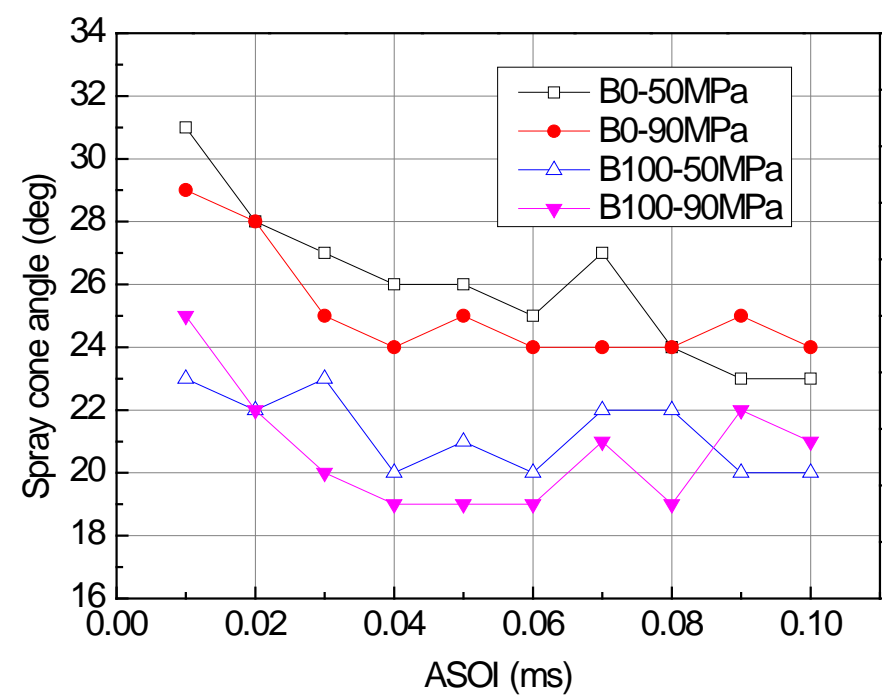

Spray area

Figure 4. Spray cone angle for diesel and biodiesel under different injection pressures

The spray area was used to represent the mixing quality between fuel and air [17]. In the present research, MATLAB software was employed to count the total effective pixels of spray image so as to represent the spray area. Figure 5 shows the values of spray area for diesel and biodiesel under different injection pressures. The results demonstrate that the spray area increases with the increase of ASOI, because the spray tip penetration becomes longer as stated in Figure 3. By comparing diesel and biodiesel under the same injection pressure, it can be found that the difference of spray areas between diesel and biodiesel is not obvious, because the lower surface tension and viscosity for diesel are good for enlarging the spray cone angle, but the diesel holds a shorter spray tip penetration. In addition, for the same fuel, the spray area increases as the injection pressure increases, because the continuously increasing injection pressure improves the development of spray tip penetration for diesel and biodiesel.

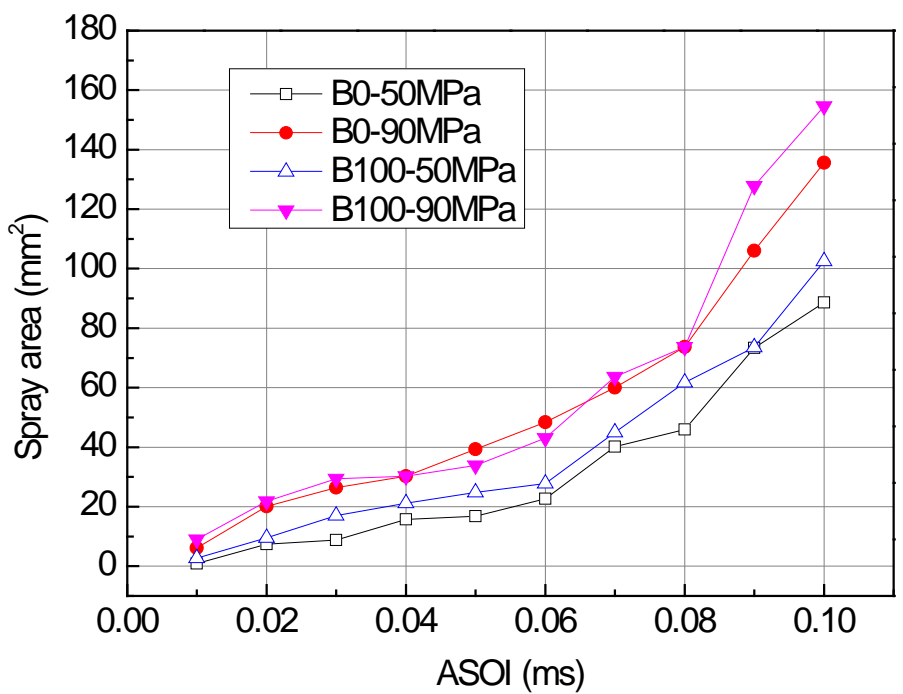

Figure 5. Spray areas for diesel and biodiesel at various injection pressures

Spray volume

The spray volume was of great importance in assessing the air entrainment mixing quality, and it can be calculated by using the following equation[18]:

$\mathrm{V}=(\pi / 3) S^{3}\left[\tan ^{2}(\theta / 2)\right] \frac{1+2 \tan (\theta / 2)}{[1+\tan (\theta / 2)]^{3}}$

(1)

In the equation, $\mathrm{S}$ represents the spray tip penetration and $\theta$ the spray cone angle respectively. Figure 6 shows the spray volumes for diesel and biodiesel under different injection pressures. It can be found in Figure 6 , the spray volume increases slowly before $0.08 \mathrm{~ms}$ (ASOI) for both fuels, and then increases dramatically after $0.08 \mathrm{~ms}$ 
(ASOI).Moreover, the spray volume of the biodiesel is higher than that of diesel at the injection pressure of $90 \mathrm{MPa}$, because higher density and viscosity of biodiesel can lead to higher inertia and fuel injection quantity. Thus, as the spray tip penetration increase as shown in Figure 3, the spray volume, in turn, increases. In addition, the spray volume can be enlarged by increasing the injection pressure at the same ASOI. Because the higher injection pressure can improve the jet momentum as well as strengthen the velocity at the nozzle exit, and result in the longer spray tip penetration. Furthermore, it can also enhance the interaction between fuel and air and thus further increase the spray volume.

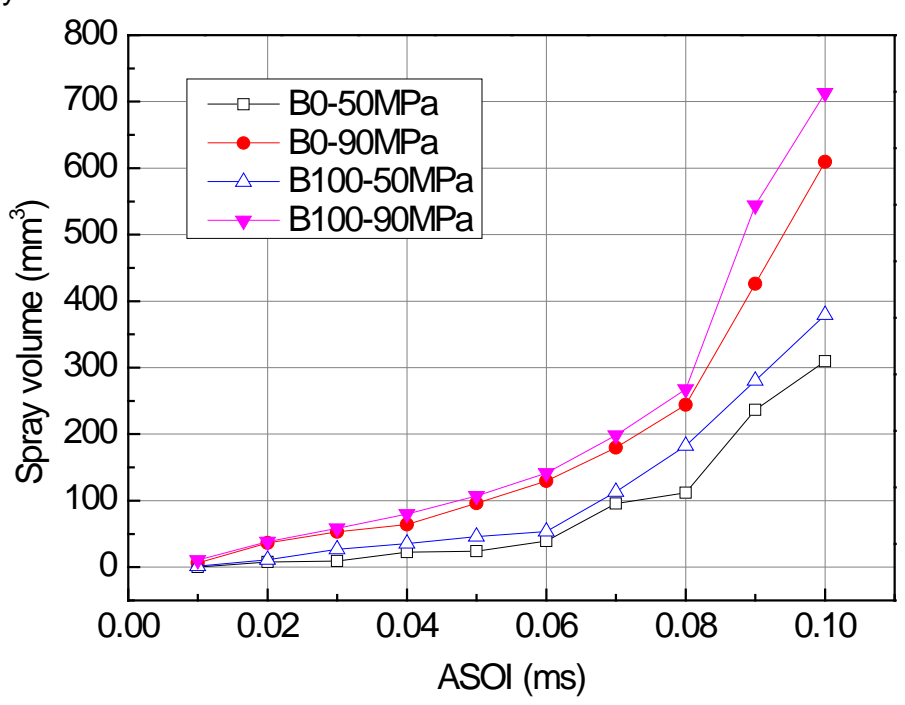

Figure 6. Spray volumes for diesel and biodiesel under different injection pressures

\section{Conclusions}

In this research, the early stage spray characteristics with diesel and biodiesel were investigated in depth under different injection conditions with a laser-based Mie-scattering method in a constant volume chamber. Main conclusions in our research are as follows:

(1) The spray tip penetration for biodiesel is longer than that for diesel at the early stage spray under the same injection pressure. Because the viscosity and surface tension of biodiesel is higher than that of diesel, which caused higher momentum at the nozzle exit as well as the higher friction between the fuel and orifice inner wall surface. In addition, the high injection pressure can enlarge the early stage spray tip penetration for both fuels.

(2) In comparison, the early stage spray cone angle for biodiesel is narrower than that for diesel. The early stage spray cone angle is especially higher than biodiesel by $25.8 \%$ after start of injection time of $0.01 \mathrm{~ms}$ under the injection pressure of $50 \mathrm{MPa}$, because the higher surface tension and viscosity of biodiesel will inhibit the collapse of spray at the initial stage spray, and the internal cavitation flow also play an important role on the spray cone angle.

(3) The difference of early stage spray area between diesel and biodiesel is not obvious under the same injection pressure. The low surface tension and viscosity of diesel can enlarge spray cone angle and hold short spray tip penetration.

(4) Because of higher injection quantity and spray tip penetration for biodiesel, the spray volume for biodiesel is larger than that for diesel under the same injection pressure. In addition, the spray volume can be enlarged by increasing the injection pressure for diesel and biodiesel.

\section{Acknowledgements}

This work was supported by the contribution of China postdoctoral fund projects [grant number2013M530236]; The projects of 'Six talent peak' [grant number 2014-ZBZZ-014]; Research start-up found projects of Jiangsu university [grant number 13JDG104]; Natural Science Foundation of Jiangsu Province of China [grant number BK20150520]; The Priority Academic Program Development of Jiangsu Higher Education Institutions [PAPD].

\section{References}

References should be indicated in the text by full sized numbers enclosed within square brackets. Use different formats for journals[19], books[20], symposium proceedings[21]and web pages[22] as illustrated in the examples below. You may use "ASME" citation style in Endnote. 
[1] Payri, R., Salvador, F., Gimeno, J., and De la Morena, J., 2009, "Effects of nozzle geometry on direct injection diesel engine combustion process," Applied Thermal Engineering, 29(10), pp. 2051-2060.

[2] Jung, D., Wang, W., Knafl, A., Jacobs, T., Hu, S. J., and Assanis, D., 2008, "Experimental investigation of abrasive flow machining effects on injector nozzle geometries, engine performance, and emissions in a DI diesel engine," International Journal of Automotive Technology, 9(1), pp. 9-15.

[3] Payri, R., Salvador, F., Gimeno, J., and Viera, J., 2015, "Experimental analysis on the influence of nozzle geometry over the dispersion of liquid n-dodecane sprays. Front," Mech. Eng, 1, p. 13.

[4] Yaliwal, V., Banapurmath, N., Gireesh, N., Hosmath, R., Donateo, T., and Tewari, P., 2016, "Effect of nozzle and combustion chamber geometry on the performance of a diesel engine operated on dual fuel mode using renewable fuels," Renewable Energy, 93, pp. 483-501.

[5] Lahane, S., and Subramanian, K., 2015, "Effect of different percentages of biodiesel-diesel blends on injection, spray, combustion, performance, and emission characteristics of a diesel engine," Fuel, 139, pp. 537545.

[6] Özener, O., Yüksek, L., Ergenç, A. T., and Özkan, M., 2014, "Effects of soybean biodiesel on a DI diesel engine performance, emission and combustion characteristics," Fuel, 115, pp. 875-883.

[7] Yilmaz, N., Vigil, F. M., Benalil, K., Davis, S. M., and Calva, A., 2014, "Effect of biodiesel-butanol fuel blends on emissions and performance characteristics of a diesel engine," Fuel, 135, pp. 46-50.

[8] Chauhan, B. S., Kumar, N., and Cho, H. M., 2012, "A study on the performance and emission of a diesel engine fueled with Jatropha biodiesel oil and its blends," Fuel \& Energy Abstracts, 37(1), pp. 616-622.

[9] Sanli, H., Canakci, M., Alptekin, E., Turkcan, A., and Ozsezen, A. N., 2015, "Effects of waste frying oil based methyl and ethyl ester biodiesel fuels on the performance, combustion and emission characteristics of a DI diesel engine," Fuel, 159, pp. 179-187.

[10] Wang, Z. M., Xu, H. M., Jiang, C. Z., and Wyszynski, M. L., 2016, "Experimental study on microscopic and macroscopic characteristics of diesel spray with split injection," Fuel, 174, pp. 140-152.

[11] Wang, Z. M., Ding, H. C., Ma, X., Xu, H. M., and Wyszynski, M. L., 2016, "Ultra-high speed imaging study of the diesel spray close to the injector tip at the initial opening stage with single injection," Applied Energy, 165, pp. 335-344.

[12] Wang, Z. W., Chen, X., Vuilleumier, D., Huang, S., and Tang, J., 2016, "Experimental Study on Spray Characteristics Of Emulsified Diesel Blending with Water In a Constant Volume Chamber," Atomization And Sprays, 26(6), pp. 513-533.

[13] Mo, J., Tang, C. L., Li, J. G., Guan, L., and Huang, Z. H., 2016, "Experimental investigation on the effect of nbutanol blending on spray characteristics of soybean biodiesel in a common-rail fuel injection system," Fuel, 182 , pp. 391-401.

[14] Li, Y. F., and Xu, H. M., 2016, "Experimental study of temporal evolution of initial stage diesel spray under varied conditions," Fuel, 171, pp. 44-53.

[15] Ding, H. C., Wang, Z. M., Li, Y. F., Xu, H. M., and Zuo, C. J., 2016, "Initial dynamic development of fuel spray analyzed by ultra high speed imaging," Fuel, 169, pp. 99-110.

[16] Xie, H. Z., Song, L. B., Xie, Y. Z., Pi, D., Shao, C. Y., and Lin, Q. Z., 2015, "An Experimental Study on the Macroscopic Spray Characteristics of Biodiesel and Diesel in a Constant Volume Chamber," Energies, 8(6), pp. 5952-5972.

[17] Yuan, W., Hansen, A., and Zhang, Q., 2009, "Predicting the temperature dependent viscosity of biodiesel fuels," Fuel, 88(6), pp. 1120-1126.

[18] Delacourt, E., Desmet, B., and Besson, B., 2005, "Characterisation of very high pressure diesel sprays using digital imaging techniques," Fuel, 84(7), pp. 859-867.

[19] Lee, C. H., and Reitz, R. D., 1999, Atomization and Sprays, 9, pp. 497-517.

[20] Wilcox, D. C., 1993, "Turbulence Modeling for CFD."

[21] Lampa, A., and Fritsching, U., Sep. 5.-7. 2011, 24th European Conference on Liquid Atomization and Spray Systems.

[22] Kastengren, A. L., Powell, C. F., Wang, Y., Im, K.-S., and Wang, J., 2009, "X-ray radiography measurements of diesel spray structure at engine-like ambient density," Atomization and Sprays, 19(11). 